\title{
Comparison of internal and external threads pitch diameter measurement by using conventional methods and CMM's
}

\author{
I. Ahmet Yüksel $^{1 *}$, T. Oytun K1lınç ${ }^{1}$, K. Berk Sönmez ${ }^{1}$, and Sinem Ön Aktan ${ }^{1}$ \\ ${ }^{1}$ Department of Laboratories and Calibration Management, Roketsan Missiles Industries Inc., 06780 \\ Ankara, Turkey
}

\begin{abstract}
Threads are very frequent and critical connection methods of components to build final products as per desired technical requirements. As it is used for very wide numbers of applications and industries, tolerances and thread structure differ as per requirements of applied areas. After theoretical decision of threaded parts, one hard task is to manufacture this thread as required. Correct flank angle, pitch diameter, pitch, height, major/minor diameters shall be obtained to receive desired mechanical connection properties. So as a result of all importance of threaded connection, it is also important to control thread properties. In this study it is aimed to show that as a result of significant development on sensor and probing technology, Coordinate Measuring Machines (CMMs) are good alternatives of conventional methods by considering accuracy, time requirement, setup requirements, and ease of application. In order to evaluate competence of regular bridge type CMMs regarding simple pitch diameter measurement, results of pitch diameter from symmetric thread with $30^{\circ}$ flank angles will be taken by 1D length measurement device and bridge type CMM to compare. Comparison of conventional methods and CMM's result shows that CMMs also provide accurate and precise results and can be used for calibration of gages as an alternative method with a number of advantages which are shown by this study.
\end{abstract}

\section{Introduction}

For many industries such as defense, space \& aviation and automotive etc. threaded connections are selected very frequently due to construction to be built and as a result of importance of each connection, many control points at wide number of product are placed. Bolts and screws play an important role in the performance of machinery. The majority of these fasteners are subjected to fluctuating loads, leading to the well-known phenomenon of fatigue which is responsible for most of the premature failure in bolts. There are many parameters such as thread pitch, thread angle, root radius and material, which can affect the performance of a bolt or screw [1].

\footnotetext{
* Corresponding author : ahmet.yuksel@,roketsan.com.tr
} 
So, design of threads is directly related to mechanical properties of connection and as a result of that, improper control of them can cause serious problems. For thread control, threaded ring and plug gages are used as most common control method of threads on final products due to practical application problems of measurements and high number of control points by considering time requirements. So GO and NO-GO thread gages are used to control pitch diameter lies within tolerances derived from related design standard of threads up to approximately $150 \mathrm{~mm}$ diameters. For upper diameters, alternative measurement devices are used due to high cost of gages at these sizes [2]. Modified snap or indicating gages or measurement of thread elements may should be considered instead of limit gages.

Ring and plug gages shall be calibrated periodically due to abrasion during usage, especially GO gages may have abrasion on their pitch diameter since they are used to control of maximum material condition of product threads and this may cause rejection of proper products or acceptance of not ok ones. It is possible for two individual limit gages of the same type to be at opposite extremes of the gage tolerance permitted, and borderline product thread accepted by one gage could be rejected by another. [2] So the routine calibration of thread gauges is both economically and technically an important matter beside their economic value [3].

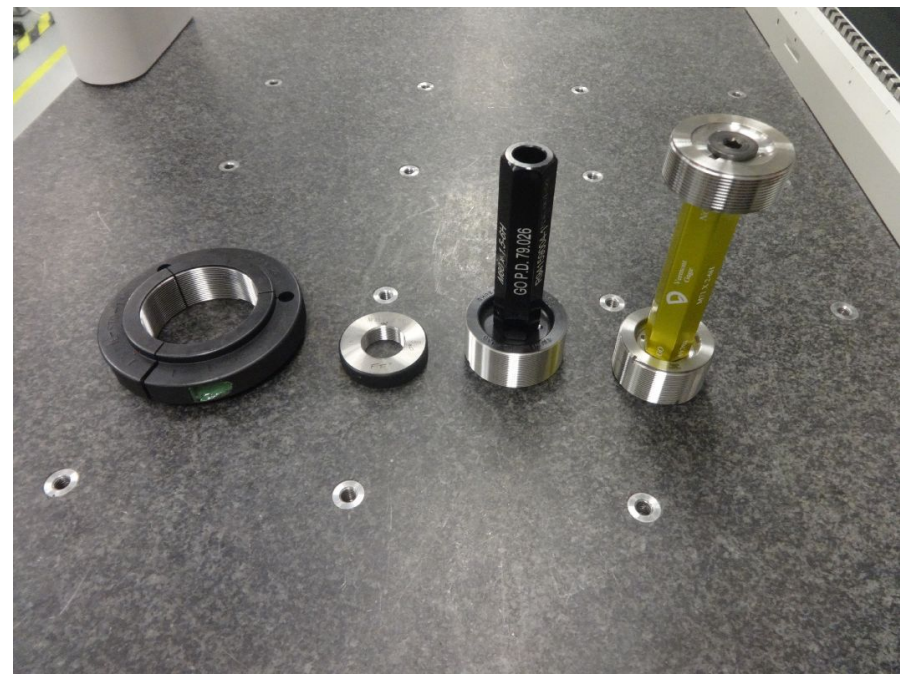

Fig. 1. Ring and plug thread gauges.

As an advantage of developed technology on CMMs and dedicated software for data collecting, CMMs can be used as an alternative methods by the help of spherical probes. CMMs can provide accurate and quick measurement for high numbers of gages and threads. A study introduced a new method of calibration of thread gauges on CMM by using special purpose needle-like probe with a similar measurement uncertainty when comparing with usual method [4]. Also, another study compared measuring methods of thread ring calibration by using coordinate measurement machines and usual methods. Furthermore, in the same study, measurement uncertainty approaches are discussed; contribution sources are shown in details for CMM applications [5].

In order to compare competence of coordinate measuring machines for thread simple pitch diameter measurements, comparison will be performed on two ring gages and two plug gages which have ANSI/ASME design. Also uncertainty approaches of both methods will be discussed. 
Provided results will be evaluated with a statistical method to understand competency of methods as per related international standard which is used to determine competence of laboratories at Inter-laboratory comparison tests.

\section{Method and application}

Regarding thread simple pitch diameter measurement, many methods are available. Mostly, mechanical probing techniques are used to determine pitch diameter for long years up to now. For external threads, calibration wires and for ring threads, T- type ball styluses are being used.

However, even this methods are available for long years up to now, an international inter-laboratory comparison (ILC) organization showed that given results by participant laboratory were different, which means that the calibration results gained from different machines of individual laboratories did not match [5]. Due to application difficulties of conventional methods, results of each laboratory may differ and also uncertainty budgets may have some differences.

In this section, method and application details of conventional methods and CMM application will be given. Furthermore, uncertainty approaches will be discussed over example practices on two ring gages whose designation respectively, M72 x $2-6 \mathrm{~g}$ NOGO gauge and M45x1,5-6g NOGO gauge and two plug gages whose designation respectively M100x2-6H GO gauge and M15x1,5 -6H GO gauge. These gauges have ANSI/ASME B1.16 metric design and tolerances bandwidths are totally 8 to 10 microns [6]. Flank angles are 30 degrees and thread geometry is symmetrical as given below at Fig.2.

Table 1. Total tolerance bandwidth.

\begin{tabular}{|c|c|}
\hline Designation of Gauges & $\begin{array}{c}\text { Total Tolerance } \\
\text { Bandwidths of Pitch } \\
\text { Diameter }(\mu \mathrm{m})\end{array}$ \\
\hline M100 x 2-6H GO & 10 \\
\hline M15 x 1,5-6H GO & 8 \\
\hline M72 x 2-6g NOGO & 15 \\
\hline M45 x 1,5-6g NOGO & 15 \\
\hline
\end{tabular}

Categories of calibration of thread gages are listed as three different categories for mechanical probing techniques. As it is stated on Euromet Guide, for the first calibration of a thread gauge, the measurement of pitch and thread angle is strongly recommended, without considering calibration category of the pitch diameter which is categorized as simple pitch diameter, Pitch Diameter, Virtual pitch diameter [3]. Uncertainty budgets shall be created by considering accepted assumption as per each category. In this study, with all techniques, simple pitch diameter will be measured and so thread angle and pitch of thread will be assumed as nominal. Calculation of simple pitch diameter by accepting angle and pitch of thread as nominal increases uncertainty budget. For calculation exact probe diameters are used. 


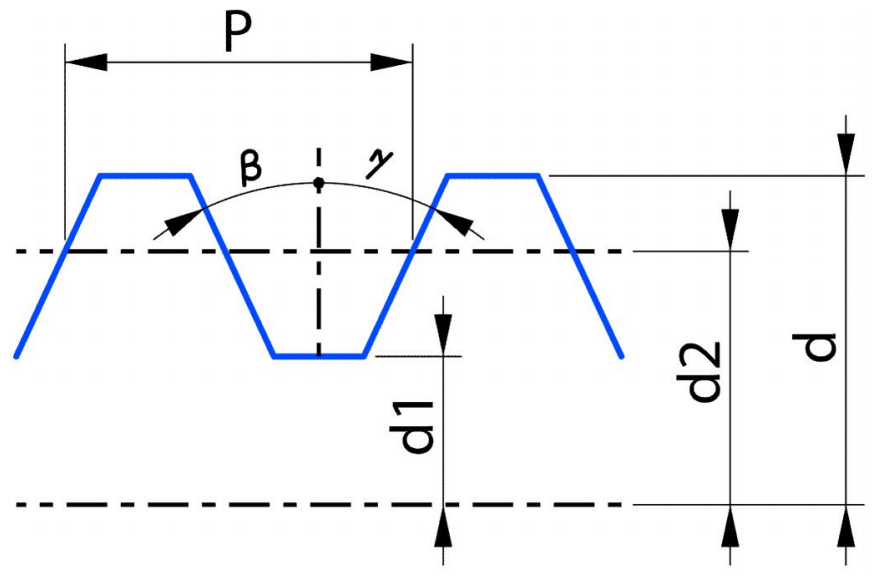

Fig. 2. Geometrical features of a thread profile.

$\mathrm{P} \quad=$ Pitch

$\mathrm{d}_{2}=$ Pitch Diameter

$\mathrm{d}=$ Major diameter

$\mathrm{d}_{1}=$ Minor diameter

$\gamma, \beta=$ Flank angle

$\mathrm{a}=\gamma+\beta$

For all applications, it is important to perform measurements after thermal balance of products. So before measurements, products to be measured should stay in measurement room where should have temperature between $20^{\circ} \pm 1^{\circ}$ Celsius for seconder level laboratories and relative humidity should be remained between $\% 45 \pm 15$. Also it is important to perform measurement after cleaning of gages by the help of a proper liquid such as alcohol gently by mean of a brush and another similar equipment. Cleaning of measurement device is also important. So before measurement it should be ensured that table and anvils of device and probes are clean enough for both methods as a basic requirements of metrology science.

Values shall be taken by applying 2 Newton forces for conventional method and $0.2 \mathrm{~N}$ for values taken by CMM. Comparison results will be declared at $0.2 \mathrm{~N}$ for both applications.

\subsection{Pitch diameter measurement of internal threads by using two ball stylus}

Pitch diameter measurements of internal threads are more complicated than external threads due to construction of internal thread which does not allow easy probing like external threads. Pitch diameter of ring gages can be measured by using universal high precision length measuring devices by the help of double-sided spherical T-type stylus as illustrated below Fig.4.

For calculation of pitch diameter of one thread, exact length of T- type stylus which will called as $\mathrm{C}$ values, should be known precisely. In order to determine exact $\mathrm{C}$ value of $\mathrm{T}$ probe, an internal plain ring or gauge block shall be measured after aligning table as per probe axis. Reference ring gages' geometrical features are also important to reduce error due to misalignment of measurement table to probing direction.

After obtaining $\mathrm{C}$ value which is illustrated at Fig.4, in order to calculate $\mathrm{m}$ value which will be used as an input for simple pitch diameter calculation, Eq. 1 shall be used. After obtaining $\mathrm{m}$ value, pitch diameter shall be calculated by using below Eq. (3). In this study, 
pitch and angles are considered as nominal since comparison will be performed over simple pitch diameter results however exact ball diameter is used.

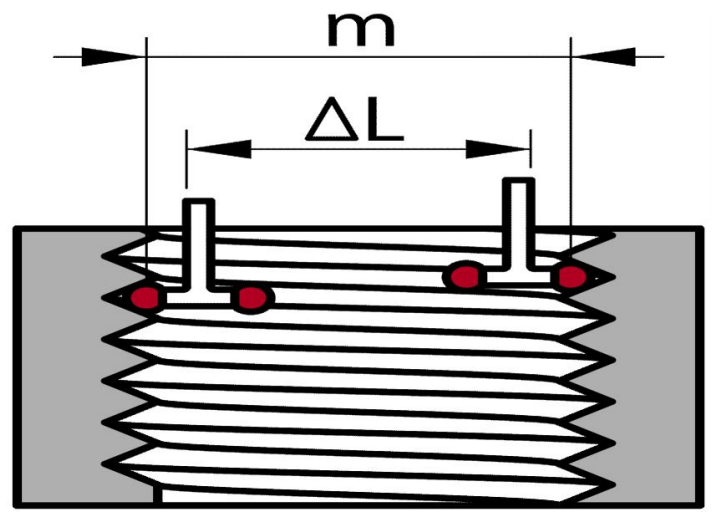

Fig. 3. Internal thread measurement by using T-Probe.

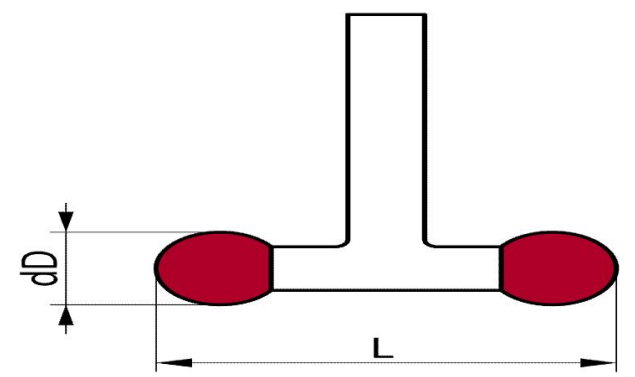

Fig. 4. T-Probe for internal thread measurements.

$$
\mathrm{m}=\Delta \mathrm{L}+\mathrm{C}-\mathrm{d}_{\mathrm{D}}
$$

In this method, selected ball diameter shall fit between two threads perfectly. If selection of ball diameter is done within ideal conditions, in this case it is assumed that pitch diameter lies at point where thread flanks and ball contacting. For symmetric thread calibration, best ball or wire diameter shall be calculated by using below Eq. 2. In case when best diameter is not available, closest diameter shall be selected by considering advise of related standards. Different diameters of probing elements will cause errors while determining pitch diameter of thread. Also material of probe is important, since all materials show different deformation behavior under forces.

$$
\mathrm{d}_{\mathrm{D}}=\mathrm{P} / 2 \cos (\alpha / 2)
$$

During best wire diameter selection a range $\mathrm{H} / 8$ approximately can be acceptable if best diameter is not available [7]. Diameter difference between maximum and minimum allowable probe diameter should not exceed $\mathrm{H} / 8$ value of one thread. Selection of improper probe diameter causes deviation while determining pitch diameter of one thread. For accurate measurement, closest diameter to ideal diameter should be used and in case best diameter is not available, a diameter which is within allowable range should be used. Calibration of probe diameter is also important since exact probe diameter should be used for accurate measurements. If probe diameter which is used for calculation is different than 
real diameter, this would cause error while calculation. For better results and low uncertainty budget, it is recommended to calibrate probes with low uncertainty value.

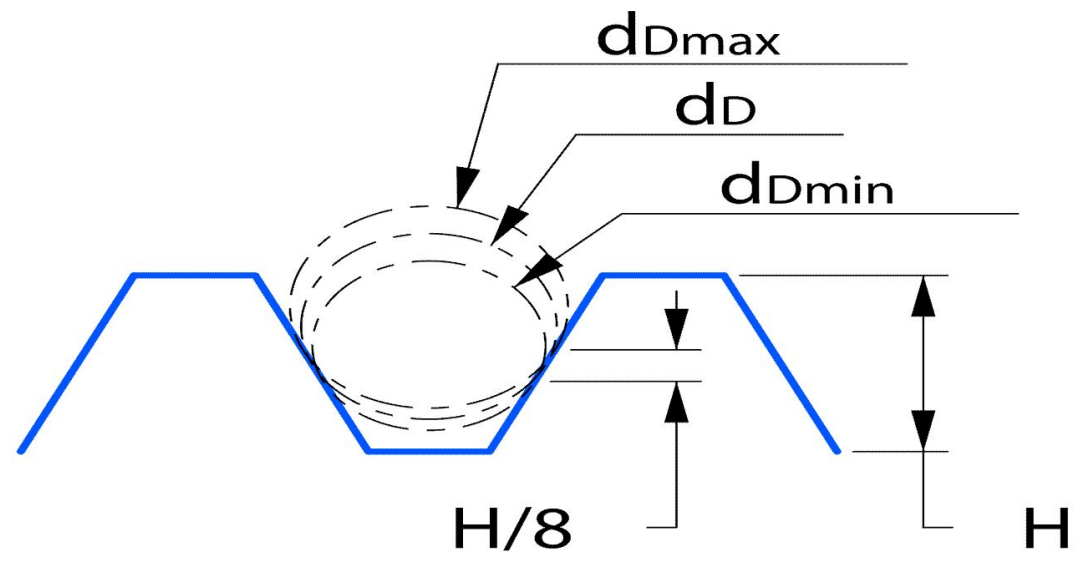

Fig.5. Best diameter range.

$$
\mathrm{d}_{2}, \mathrm{D}_{2}=\mathrm{m}+\left[\mathrm{d}_{\mathrm{D}} / \sin (\mathrm{a} / 2)\right]-[\mathrm{P} \mathrm{x} \cot (\mathrm{a} / 2) / 2]+\mathrm{A}_{1}-\mathrm{A}_{2}-\delta \mathrm{D}_{\mathrm{p}}-\delta \mathrm{D}_{\mathrm{a}}
$$

In this equation A1 represents Rake Correction and A2 represents probe deformation correction which should be calculated separately and include in Eq. (3) and Eq. (5). Furthermore, Pitch error correction is shown by $\delta D_{p}$, thread angle correction $\delta D_{\alpha}$. These two values shall be accepted as 0 for simple pitch diameter measurements. These A1, A2, $\delta \mathrm{D}_{\alpha}$ and $\delta \mathrm{D}_{\mathrm{p}}$ parameters are also valid for plug gage measurements as it is shown at Eq. (5).

For A2 correction, as an alternative method which is different from known equation, measurements can be performed at different forces to understand force effect on probing. After obtaining diameters for different applied forces, an equation can be created which is dependent to force and diameter variable. After that $0 \mathrm{~N}$ force can be calculated to remove effect of probe deformation due to applied for. This method can be applied for plug and ring gages by considering Eq. (3) and Eq. (5).

In order to understand and evaluate form of thread geometry, measurement shall be repeated after rotating ring gauge by $90^{\circ}$. Form error shall be calculated and added to uncertainty budget for further evaluation.

\subsection{Pitch diameter measurement of external threads by using 3 wires methods}

In order to perform measurement of simple pitch diameter of one thread at universal length measurement device, device linear scale should be set by using a plain gage or gauge block whose diameter or dimension is close to thread plug gauge diameter which is intended to be calibrated. During measuring reference ring plain gauge or gauge block, alignment of table should be adjusted as per measurement face's axes.

After successful set and alignment of table, 3 wires shall be selected as per given Eq. 2. In case best diameter is not available, closest diameter should be selected by considering allowable range which is mentioned at section 2.1 in detailed. After selection of wires, wires shall be located as seen below Fig. 6. Fir this method, application of small pitches are harder since it is very hard to see and locate very small wires into small threads. For correct 
applications, lightening and magnifying glasses can be used to observe implementation of wires between thread perfectly.

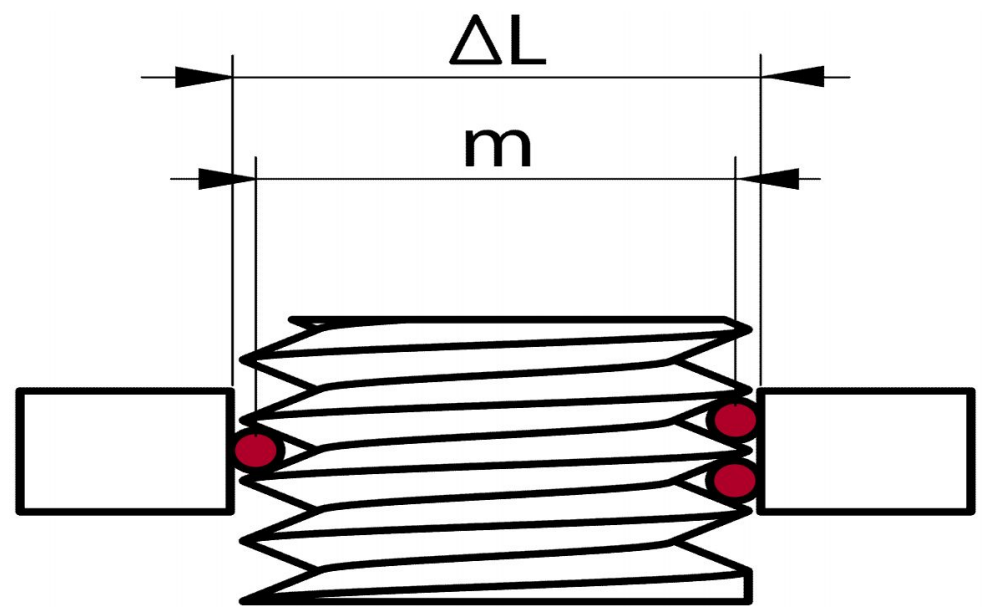

Fig.6. Three wires method for external threads.

$$
\mathrm{m}=\Delta \mathrm{L}-\mathrm{d}_{\mathrm{D}}
$$

In this method, two wires shall be located at anvils of device; one wire shall be located at moving measurement arm of device. Two wires are used to adjust axis angle of plug gage according to measurement arm's axis. Two wires method also available for external thread measurements.

By locating three wires as seen at Fig. 6. measurement shall be performed to take length over wires. After taking measurements over wires, by obtaining $\mathrm{m}$ value from equation (4) below equation shall be used for pitch diameter calculation with corrections.

$$
\mathrm{d}_{2}, \mathrm{D}_{2}=\mathrm{m}-\left[\mathrm{d}_{\mathrm{D}} / \sin (\mathrm{a} / 2)\right]+\left[\mathrm{P}^{*} \cot (\mathrm{a} / 2) / 2\right]-\mathrm{A}_{1}+\mathrm{A}_{2}+\delta \mathrm{D}_{\mathrm{p}}+\delta \mathrm{D}_{\mathrm{a}}
$$

In order to evaluate and know form of thread, measurement shall be repeated after rotating plug gage by 90 degrees. Form error shall be calculated and added to uncertainty budget for further evaluation.

\subsection{Pitch diameter measurement by using CMM with star type ball probe}

After significant development on measurement systems during last decades, CMMs are started to be used for calibration purposes of gauges not for only quality control purposes of products. CMMs offer accurate results with ease of application and mostly remove errors due to operator skills. Measurements by CMMs, take less time when comparing with conventional methods. Furthermore, repeatability and reproducibility can be obtained by $\mathrm{CNC}$ features of CMM.

CMMs can be used for measurement of pitch diameter and also for measurement of flank angles and pitch of thread. For pitch diameter measurement it is important to be sure that taken point by CMM shall be performed after probe located into middle of two threads perfectly as illustrated at Fig. 7. By the help of "self-centering" function of one dedicated software (Zeiss Calypso), it is possible to collect data after placing probe exactly into the middle of two threads. Simply according to given Fig. 7, after touching one flank, probe is only moving through the $\mathrm{y}$ and $\mathrm{x}$ axis until it perfectly fits between two threads. In detailed, after 
touching one flank, CMM searches for second force from other flank and move until these two forces equal to each other. Without this feature, taken point would be located at place where probe touches first and this would cause deviation on pitch diameter measurements. From illustration below, without this feature of CMMs. taking point would be deviated as differences between position 1 and 2 on y axis.

\section{Probing Direction}

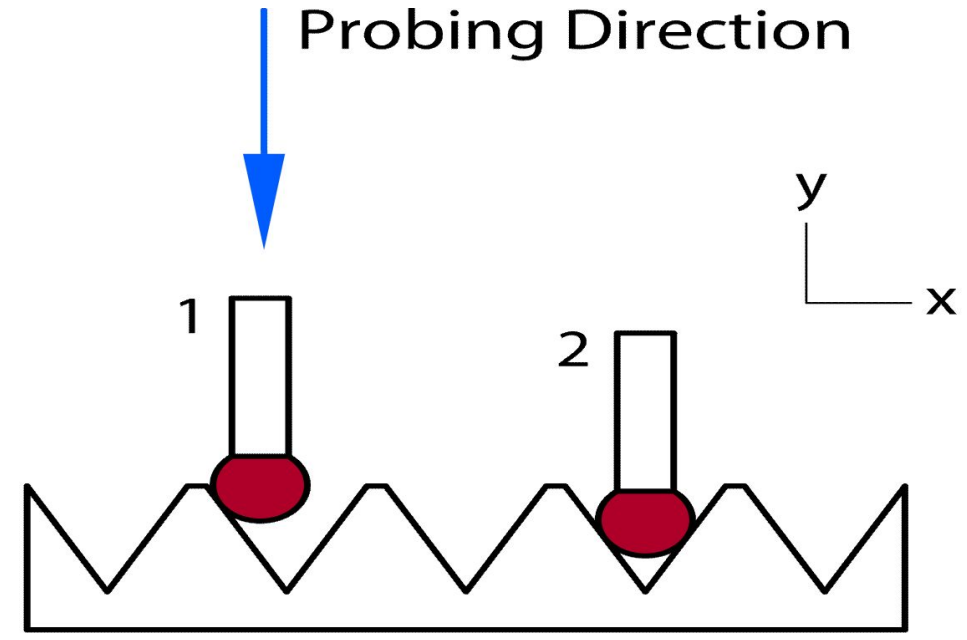

Fig.7. Self-Centering method.

Regarding CMM accuracies, in order to reduce uncertainty contribution which comes from CMM device itself, a verification measurement by using etalon ring or a calibration class block gauge can be performed at table of CMM where thread calibration will be performed. After this verification measurement, deviation between certificate of etalon and CMM result can be added to budget as uncertainty. It should be also considered that uncertainty which comes from certificate of used etalon also shall be added to budget.

Furthermore, after probe calibration of star type stylus which is calculated and selected as per pitch value of thread in the light of (2) numbered equation can be obtained by using a reference plain gage exact length of two ball stylus can be exactly measured and used for further calculations as it is shown at Fig. 9.

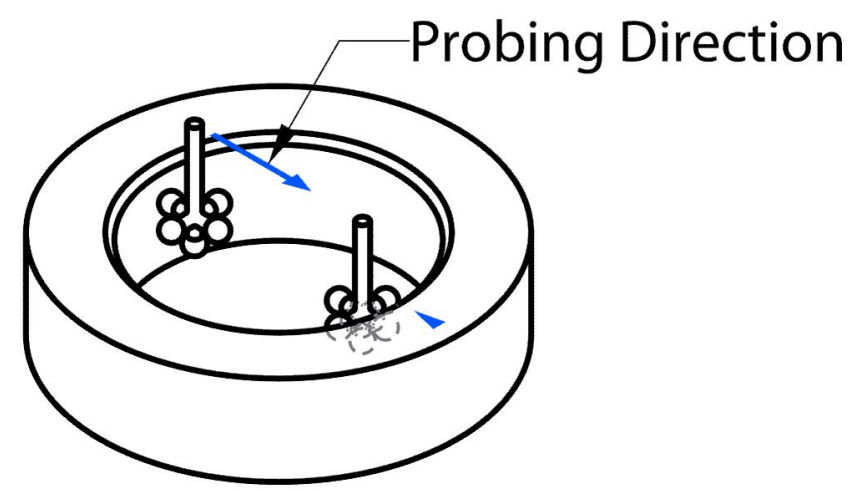

Fig.8. Determination of probe length.

For pitch diameter measurements following steps shall be performed and further calculations shall be executed by using same equation (5) and (3) respectively for thread plug and thread ring gages which are also used for usual methods. 
- Axis of thread cylinder shall be perpendicular to CMM table as much as possible. Original $\mathrm{z}$ axis of CMM and gauge cylinder axis shall be parallel to each other as much as possible.

- Best diameter shall be calculated and stylus system shall be selected as per this best probe diameter.

- Alignment of gage shall be performed by using one surface which is selected from parallel surface of gauge and a cylinder which is constructed by using 8 points taken from upper and lower side of gage with 90 degree offsets with self-centering feature of CMM with dedicated software as shown at below illustration. By the help of alignment, product axis and device axes aligned to each other perfectly as theoretical. In this method 4 point from upper side and 4 point from lower side shall be taken. Cylinder shall be constructed theoretically from separate 8 points to be used as alignment feature.
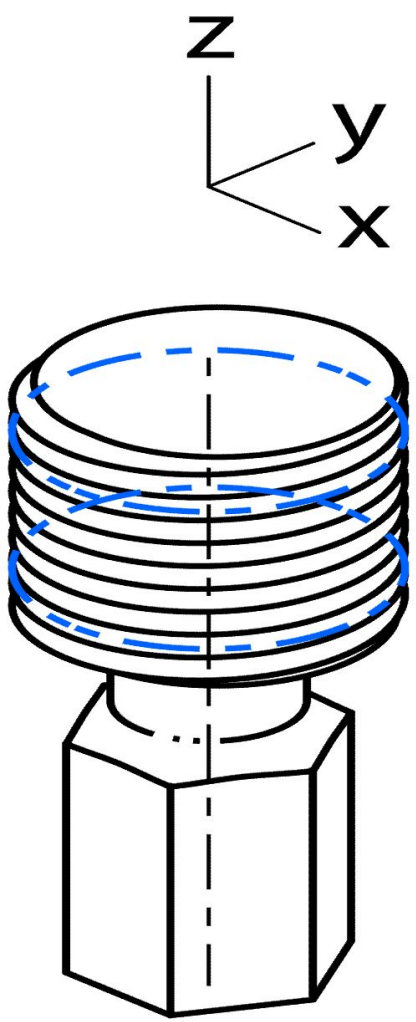

Fig. 9. Gage alignment on CMM table.

After successful alignment of gage as shown Fig. 9, head of CMM shall be sent to P1 point for pitch diameter measurement of ring or plug gages on $\mathrm{X}$ axis as shown Fig. 10. First point shall be taken and stylus system shall be moved on only axis where diameter will be measured to take second point P2. After taking two points, P1 and P2 successfully, diameter between $\mathrm{P} 3$ and $\mathrm{P} 4$ shall be taken for form error calculations. All points shall be taken by using self-centering feature of software and values shall be taken as mid-point of probe. In this case, value given by CMM can be considered as $\mathrm{m}$ value to determine simple pitch diameter as conventional methods. 


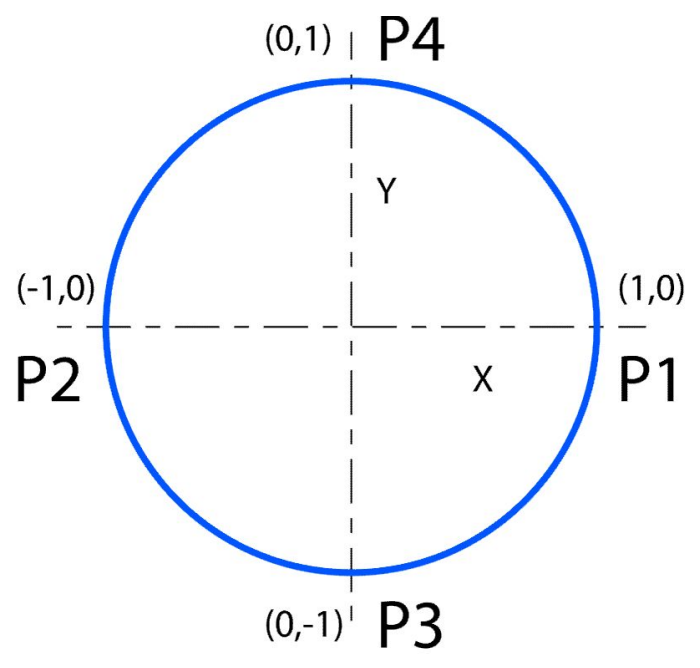

Fig.10. Top view of gages on CMM table.

Taken results from plug and ring gages which are considered as $\mathrm{m}$ value and shall be put into equations (3) and (5) to determine pitch diameter. Angle of thread and pitch will be assumed as nominal to calculate simple pitch diameter. CMM results are given as midpoint of probe when lapped into middle of two threads and probing is illustrated below at Fig. 11 and Fig. 12.

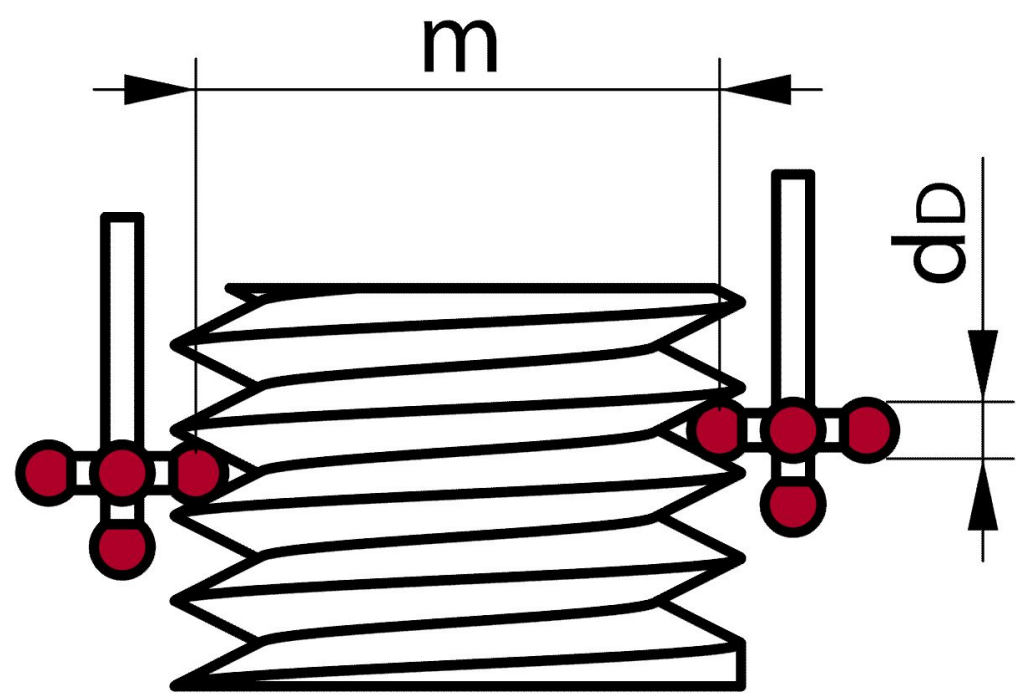

Fig. 11. Thread plug gauge pitch diameter measurement by CMM.

For internal thread measurements, in order to avoid probe collision with CMM table, ring gauges may be needed to be lifted by using a proper material. Another ring gauges can be put under of gauges which is intended to be measured. So without any collision risk, last thread pitch diameter also can be measured without any problem. 


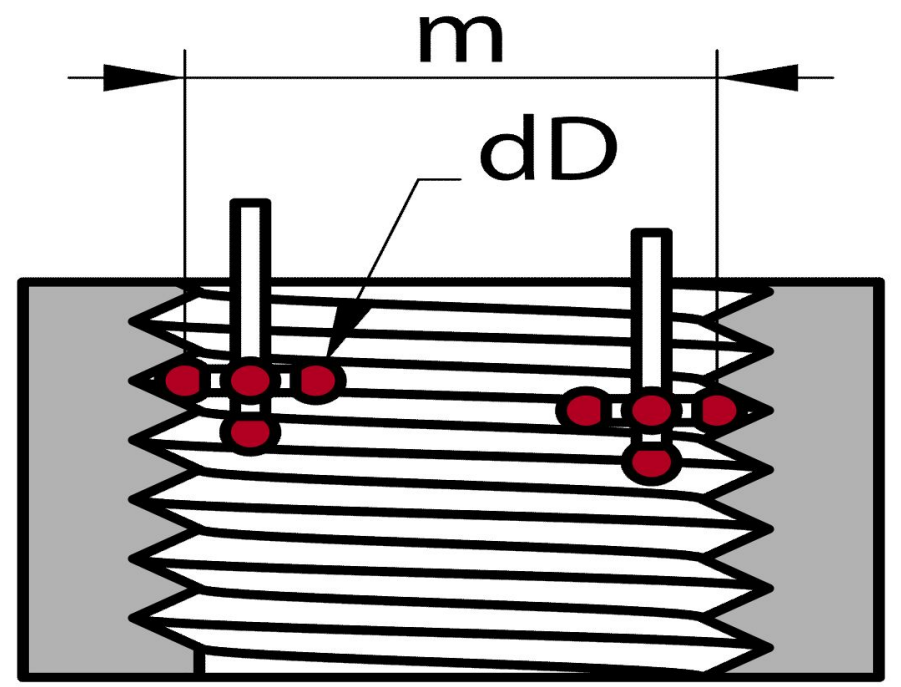

Fig.12. Thread ring gauge pitch diameter measurement by CMM.

\section{Uncertainty approaches}

For both methods' measurement uncertainty budgets will be discussed and differences will be shown by providing contributors of uncertainty. However it should be noted that, budgets can show differences due to measurement devices and also pitch diameter category to be measured. After taking measurements by using all methods and calculating expanded uncertainties will be given and compared.

\subsection{Uncertainty approaches of conventional methods}

In this study, a 1D universal length measurement machine used for collecting data from ring and plug gages in order to determine pitch diameter. Device accuracy is given as 0.08 Micron by manufacturer as it is also valid after last calibration by the help of verification inspection tests and etalons which are used to set device's linear scale are calibrated with a very low uncertainty. Furthermore, used $\mathrm{T}$ type ball probes and three wires sets are calibrated with very low uncertainty.

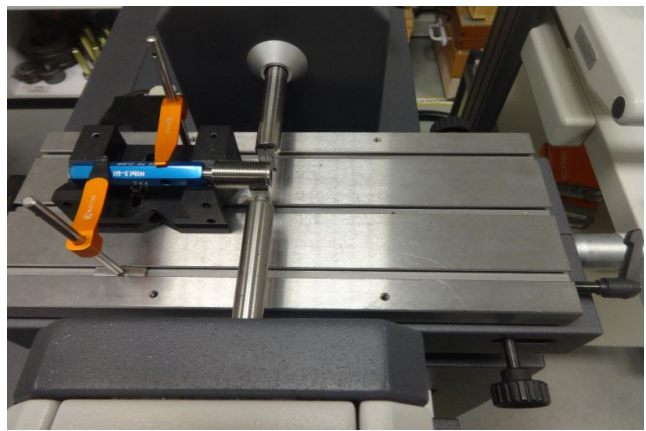

Fig.13. Universal length measurement device.

As also discussed at Euromet Guide [3], uncertainty budget for ring thread gauge calibration is given below. 
- Reference devices $(\Delta \mathrm{L})$

- Probe constant ( C )

- Probe $\left(\mathrm{d}_{\mathrm{D}}\right)$

- Pitch measurement (P)

- Flank angle measurement (a)

- Rake correction $\left(\mathrm{A}_{1}\right)$

- Force and deformation $\left(\mathrm{A}_{2}\right)$

- Form error $\left(\delta_{\mathrm{B}}\right)$

- Pitch error correction $\left(\delta \mathrm{D}_{\mathrm{p}}\right)$

- $\quad$ Flank angle correction $\left(\delta \mathrm{D}_{\alpha}\right)$

For plug thread gauge calibration, below contributes shall be added to budget [3].

- References devices $(\Delta \mathrm{L})$

- Wires $\left(\mathrm{d}_{\mathrm{D}}\right)$

- $\quad$ Pitch measurement (P)

- $\quad$ Thread angle measurement $(\alpha)$

- Rake correction $\left(\mathrm{A}_{1}\right)$

- Force and deformation $\left(\mathrm{A}_{2}\right)$

- Form error $\left(\delta_{\mathrm{B}}\right)$

- Pitch error correction $\left(\delta \mathrm{D}_{\mathrm{p}}\right)$

- Thread angle correction $\left(\delta \mathrm{D}_{\alpha}\right)$

\subsection{Uncertainty approaches of CMM application}

In this study, bridge type Zeiss CMM with accuracy under 1 micron is used. For data collection, Calypso 2014 software is used with self-centering function. For uncertainty calculations of CMM application, below items had been considered and calculated.

- References block gages $\left(\mathrm{D}_{\mathrm{c}}\right)$

- Thread form error $\left(\rho_{\mathrm{x}}\right)$

- $\quad$ Probing error $(p)$

- Misalignment axes and gages $(\mathrm{g})$

- CMM resolution (r)

- Error due to temperature differences for gage $\left(t_{x}\right)$

- Error due to temperature differences for references block gage $\left(t_{g}\right)$

- Repeatability $\mathrm{T}_{\mathrm{x}}$

- CMM Thermal Induced Error $\left(\mathrm{t}_{\mathrm{s}}\right)$

\section{Results and analysis}

After performing measurements with two methods, results are given for 0.2 Newton $(\mathrm{N})$ measuring force. Diameters are obtained between $0^{\circ}$ and $180^{\circ}$ for comparison from same thread. Uncertainty calculations are performed as per section 3 and given below with results. For calculations simple pitch diameter, nominal values of pitch and angle of thread had been used and exact probe diameter is used to calculate results. Both results and uncertainty values are obtained by two different accredited laboratories.

For each ring and plug types, two different pitch and nominal diameter had been selected, in order to show that CMM method validity is independent to this features of threads. 
Results are very accurate for plug gages however for ring gauge with M45 x $2-6 \mathrm{~g}$ designation, calculated diameter deviates around 2 microns others differences are under 1 micron. Result of higher deviation than other 3 gauges, can be considered as probing mistake while conventional method application. Further study may cover an interlaboratory comparison test regarding pitch diameter measurement with CMM method to detailed differences of measurement of both methods.

Table 2. Comparison of results.

\begin{tabular}{|c|c|c|c|c|}
\hline & \multicolumn{2}{|c|}{ Conventional Method } & \multicolumn{2}{c|}{ CMM } \\
\hline Gauges & $\begin{array}{c}\text { Measured } \\
\text { Simple Pitch } \\
\text { Diameter } \\
(\mathrm{mm})\end{array}$ & $\begin{array}{c}\text { Calculated Uncertainty }(\mu \mathrm{m}) \\
(\mathrm{k}=2)\end{array}$ & $\begin{array}{c}\text { Measured } \\
\text { Simple Pitch } \\
\text { Diameter }(\mathrm{mm})\end{array}$ & $\begin{array}{c}\text { Calculated } \\
\text { Uncertainty } \\
(\mu \mathrm{m}) \\
(\mathrm{k}=2)\end{array}$ \\
\hline M100x2-6H & 98,6914 & 2,6 & 98,6919 & 2,2 \\
\hline M15x1,5-6H & 14,0357 & 2,6 & 14,0360 & 2,2 \\
\hline M72x2-6g & 70,6757 & 2,8 & 70,6761 & 2 \\
\hline M45x1,5-6g & 43,8534 & 2,8 & 43,8546 & 2 \\
\hline
\end{tabular}

In order to evaluate competence of measurement results, $E_{n}$ value which is calculated by using below equation was calculated. The performances of the measurements can be evaluated with many different statistical approaches as described in ISO 13528 Standard [8]. The most commonly used statically approach is $E_{n}$ value of each measurement shall be below zero.

$$
E n=\frac{X_{a}-X b}{\sqrt{U_{a}^{2}+U_{b}^{2}}}
$$

$\mid$ En $\mid \leq 1$ means sufficient.

$|\mathrm{En}|>1$ means insufficient performance and action required from the laboratory to improve the result.

$X_{\mathrm{A}}$ : Measurement Value by mean of conventional method

$X_{\mathrm{B}}$ : Measurement Value of the Reference Laboratory

$U_{\mathrm{A}}$ : Measurement Uncertainty of the Participating Laboratory

$U_{\mathrm{B}}$ : Measurement Uncertainty of the Reference Laboratory

Since, CMM results are provided by reference laboratory and uncertainty value is smaller than conventional one, CMM result can be considered as given by reference laboratory. Conventional results will be considered as participating laboratory. Opposite version of this assumption would not change the result since absolute value of En is evaluated as per related statistical method. Further study may cover an Inter-laboratory comparison on same field with more participating laboratories.

Table 3. En Results of each pitch diameter measurement.

\begin{tabular}{|c|c|c|c|c|c|}
\hline & \multicolumn{2}{|c|}{ Results $(\mu \mathrm{m})$} & \multicolumn{2}{c|}{ Uncertainty $(\mu \mathrm{m})$} & \\
\hline Measurements & $\mathrm{X}_{\mathrm{A}}$ & $\mathrm{X}_{\mathrm{B}}$ & $\mathrm{U}_{\mathrm{A}}$ & $\mathrm{U}_{\mathrm{B}}$ & $1_{\mathrm{n}} 1$ \\
\hline M100x2-6H & 98,6914 & 98,6919 & 2,6 & 2,2 & 0,15 \\
\hline M15x1,5-6H & 14,0357 & 14,0360 & 2,6 & 2,2 & 0,09 \\
\hline M72x2-6g & 70,6757 & 70,6761 & 2,8 & 2 & 0,12 \\
\hline M45x1,5-6g & 43,8534 & 43,8546 & 2,8 & 2 & 0,35 \\
\hline
\end{tabular}




\section{Conclusion}

As a result of evaluation, it is seen that, CMMs can be considered as an alternative method for determination of simple pitch diameter when comparing obtained results and uncertainties together with $E_{n}$ values. Beside acceptable uncertainty and accuracy of CMMs' measurements, application is easier according to conventional methods. For industries where high number of threaded gauges and products are available, CMM measurement method can be implemented instead of conventional measurement machines in order to reduce measurement time and operator effects.

The valuable assistance of İ.Meral for CMM application and measurement procedure and support of Roketsan Missiles Industries Inc. and valuable assistance of C.B Çemberci are gratefully acknowledged.

\section{References}

1. G.H. Majzoobi, G.H. Farrahi, and N. Habibi, Experimental evaluation of the effect of thread pitch on fatigue life of bolts, International journal of fatigue 27, 2, 189-196, (2005)

2. American Society of Mechanical Engineering, ANSI/ASME B1.2-1983, Gage and Gaging for Unified Inch Screw Threads, (1983)

3. Guide, EURAMET Calibration, Determination of pitch diameter of parallel thread gauges by mechanical probing, EURAMET/cg-10 1 (2007)

4. S. Carmignato, L.D. Chiffre, A new method for thread calibration on coordinate measuring machines, CIRP Annals 52, 1, 447-450, (2003)

5. T.P. Merkac, B. Acko, Comparising measuring methods of pitch diameter of thread gauges and analysis of influences on the measurement results, Measurement 43, 3, 421-425, (2010)

6. American Society of Mechanical Engineering, ANSI/ASME B1.16-1984, Metric Thread Gages and Gaging for Metric Threads, (1984)

7. SIP Guide, Measurement of The Effective Diameter of Screw Threads By Means of Calibrated Wires, Societe Genevoise D'Instruments De Physique, (1988)

8. International Organization for Standardization, ISO/IEC $13528: 2015$, Statistical methods for use in proficiency testing by interlaboratory comparison, (2015) 